\title{
The effects of stress on Stroop color-word performance
}

\author{
SIDNEY H. HOCHMAN \\ QUEENS COLLEGE, CUNY
}

Based on the Hullian proposition that habit and drive combine, the effects of stress on the Stroop Color-Word Test were investigated in 48 college students, under the expectation that stress would effect performance differentially, depending upon the nature of the incongruous stimuli. Significant main effects, stress and competition, as well as their interaction, were found.

Stroop (1935), observing that it takes more time to name colors than to read color names (Brown, 1915; Lund, 1927; Ligon, 1932), proposed a technique for investigating the interfering effect of the presence of conflicting word stimuli upon naming colors (e.g., the word "blue" is printed on the color red, the task being to name the color of the ink and ignore the word). The series of tasks has proved discriminative in studies attempting to elaborate cognitive styles (Broverman \& Lazarus, 1958; Broverman, 1960), in studies comparing groups which are ordered developmentally (Comalli, Wapner, \& Werner, 1962; Schiller, 1966), and in Ss under primitivizing drugs vs placebo conditions (Wapner \& Krus, 1960).

The present study sought to vary the strength of the incorrect competing response relative to the correct response by varying the relationship between color and text. Word meanings that implicate the colors should be more interfering than simply meaningful but unrelated words; words referring directly to color should be more interfering than connotatively related words; greatest of all should be the interference of words that are themselves the names of the printed color names (Klein, 1964). Stress was applied in the form of introducing time pressures into the task. In the stress condition, the $S$ had $1 \mathrm{sec}$ to respond, while in the nonstress condition, he had 2 sec. If, on the basis of Hull's (1943) original assumption that all momentarily operative motivational factors or drives (D) combine indiscriminately with all existing habitual tendencies $(H)$ that are aroused by the stimulus situation to produce response strength (E), the stimulus situation gives rise to more than one response; the effects of increased drive, according to this assumption, are expected to depend on the strength of the to-be-learned (correct) response relative to other competing (incorrect) responses. Thus, where the correct response (naming the color) has a lower habit strength than the competing response (reading the color word), high drive (stress) would be predicted to be detrimental to performance.

\section{Method}

Four different lists of words were used. Each word was printed either in red, blue, or green. In List 1 , the words were the same as the color names, but presented in incongruent combinations of color and word ("blue" printed in red); in List 2 they were different words of the same response class (tan, gray, black); in List 3 , they were words that are not themselves color names but implicate the colors in their meaning (sky, fire, grass) and were presented in incongruent combinations with the colors; and in List 4, they were common English words not closely associated with the color names, either in meaning or in response class (put, take, heart). Each list contained 27 stimuli, the three color words each appearing nine times in random order, and presented serially, on a memory drum, each stimulus individually, in contrast to Stroop's technique where all the stimuli are made visible to the $S$ at one time. The different lists were comparable in the arrangement of word-color units. The stimuli were presented at speeds of 1 and $2 \mathrm{sec}$ duration. The Ss were 48 introductory psychology students, distributed randomly among the eight conditions, six to a group. Prior to performance on a list, each $\mathrm{S}$ was given three practice items corresponding to the content of the list, with the instructions to name the color of the ink in which the word was printed, and ignore the word. All responses were recorded and analyzed for errors (word reading, inappropriate color responses, contaminated responses, e.g., "breen," and omissions). The design was a 4 by 2 factorial consisting of four levels of response competition (Lists $1,2,3,4)$ and two levels of stress (1 and $2 \mathrm{sec}$ ).

\section{Results and Discussion}

The mean number of errors on the different lists under the two stress conditions are given in Table 1. The analysis of variance for these data shows significant differences between the two stress conditions $(\mathrm{F}=6.85, \mathrm{df}=1 / 40, \mathrm{p}<.05)$, among the lists $(F=5.41, d f=3 / 40, p<.01)$, and a significant interaction $(F=3.08$, df $=3 / 40, p<.05$ ).

The significant effects of stress, competitive lists, and their interaction are of interest from a theoretical standpoint. Interference of the words with color naming was greatest where the actual words were "red," "blue," and "green," decreased sharply with words of the same response class, decreased somewhat more with words which implicate the colors in their 
Table 1. Mean number of errors for different lists under stress and nonstress conditions

\begin{tabular}{cccccc} 
& & \multicolumn{4}{c}{ List } \\
\multirow{3}{*}{ stress } & 1 & 2 & 3 & 4 \\
& 1 sec. & 3.33 & .67 & .50 & .33 \\
& 2 sec. & .50 & .17 & .17 & 0 \\
\hline
\end{tabular}

meaning, and still more where they are not associated either in meaning or response class. Hull's assumption and Klein's hypothesis regarding the delay in color naming being produced by the necessity of "holding back" a competing response is in agreement with the data, where the number of errors sharply decreased under the $2 \mathrm{sec}$ condition, and from List 1 to List 4 . The effects of stress were found to be contingent on the relative strength of the incorrect response. Where the incorrect response was highly dominant (List 1 ), the Ss made the most errors. Where the Ss had a "chance" to inhibit the dominant response (nonstress condition), errors decreased. The interaction between stress and lists indicates that performance, under stress, is impaired where the dominant word-reading response was highly incompatible with the color-naming response, significantly more so than under the nonstress condition.

As observed by several investigators, besides word reading, inappropriate color responses, contaminated responses, and omissions, physical manifestations of stress and strain such as twitching, head bobbing, laughing, etc. were evident during testing under the stress condition. Gaining control of these. irrelevant responses, as well as "holding back" competing responses, may help the $S$ in reducing the interference on the color-word test.

\section{References}

BROVERMAN, D. M. Dimensions of cognitive style. J. Pers, 1960, $28,169-185$

BROVERMAN, D. M., \& LAZARUS, R. S. Individual differences in task performance under conditions of cognitive interference. J. Pers, $1958,26,94-105$.

BROWN, W. Practice in associating color-names with colors. Psychol Rev., 1915, 22, 45-55.

COMALLI, P. E. Jr., WAPNER, S., \& WERNER, H. Interference effects of Stroop color-word test in childhood, adulthood, and aging. $J$. genet. Psychol, 1962, 100, 47-53.

HULL, C. L. Principles of behavior. New York: Appleton-CenturyCrofts, 1943.

KLEIN, G. S. Semantic power measured through the interference of words with color-naming. Amer. J. PsychoL, 1964, 77, 576-588.

LIGON, E. M. A genetic study of color naming and word reading. Amer. J. Psychol, 1932, 44, 103-121.

LUND, F. H. The role of practice in speed of association. $J$. exp. Psychol, 1927, 10, 424-433.

SCHILLER, P. H. Developmental study of color-word interference. J. exp. PsychoL, 1966, 72, 105-108.

STROOP, J. R. Studies of interference in serial verbal reactions. $J$. exp. Psychol., 1935, 18, 643-662.

WAPNER, S., \& KRUS, D. M. Effects of lysergic acid diethylamide, and differences between normals and schizophrenics on the Stroop color-word test. J. Neuropsychiat., 1960, 2, 76-81.

Note

1. The author is grateful to Dr. Alfred Castaneda for his suggestions and criticisms. 